\begin{tabular}{|c|c|}
\hline Title & A ustenite memory during reverse transformation of steels at different heating rates \\
\hline Author(s) & $\begin{array}{l}\text { Saito, Genki; Nakay ama, Tomoya; Sakaguchi, Norihito; Ohno, Munekazu; Matsuura, Kiyotaka; Takeuchi, Masay oshi; } \\
\text { Sano, Taichi; Minoguchi, Koki; Y amaoka, Takuya }\end{array}$ \\
\hline Citation & $\begin{array}{l}\text { Materialia, 7, UNSP 100409 } \\
\text { https://doi.org/10.1016/.mtla.2019.100409 }\end{array}$ \\
\hline Issue Date & $2019-09$ \\
\hline Doc URL & http:/hdl .handle.net/2115/82574 \\
\hline Rights & $\begin{array}{l}\text { (O2U20. Ins manuscript versson is made avallable under the CC-BY-IVC-IVD } 4.0 \text { IIcense } \\
\text { http://treativecommons.org/icenses/py-nc-nd/4.0/ }\end{array}$ \\
\hline Rights(URL) & http://creativecommons.org/icenses/by-nc-nd/4.0/ \\
\hline Type & article (author version) \\
\hline File Information & manuscript (Saito).pdf \\
\hline
\end{tabular}

Instructions for use 


\title{
Austenite memory during reverse transformation of steels at different heating rates
}

\author{
Genki Saito ${ }^{\mathrm{a}^{*}}$, Tomoya Nakayama ${ }^{\mathrm{a}}$, Norihito Sakaguchi ${ }^{\mathrm{a}}$, Munekazu Ohno ${ }^{\mathrm{a}}$, Kiyotaka Matsuura ${ }^{\mathrm{a}}$, \\ Masayoshi Takeuchi ${ }^{\mathrm{b}}$, Taichi Sano ${ }^{\mathrm{b}}$, Koki Minoguchi $^{\mathrm{b}}$, Takuya Yamaoka ${ }^{\mathrm{b}}$ \\ ${ }^{a}$ Faculty of Engineering, Hokkaido University, Sapporo, Japan \\ ${ }^{\mathrm{b}}$ Mitsubishi Steel MFG. Co., Ltd., Tokyo, Japan
}

\begin{abstract}
(<250 words)
The austenite $(\gamma)$ structure reversely transformed from martensite in Fe- $0.55 \mathrm{C}$ mass $\% \mathrm{C}$ alloy was investigated at high temperatures using in-situ an electron backscatter diffraction (EBSD) method. When the heating rate was varied, a rapidly heating produced fine $\gamma$ grains, in contrast, a slow heating induced coarse $\gamma$ grains having the same crystal orientations as those of the prior $\gamma$ grains; known as " $\gamma$ memory". The most likely mechanism for the $\gamma$ memory could be variant restrictions owing to cementite $(\theta)$. To investigate the effect of $\theta$ on the $\gamma$ memory, the sample was tempered at $700{ }^{\circ} \mathrm{C}$ for $24 \mathrm{~h}$ and $\theta$ was precipitated. The tempered sample exhibited the $\gamma$ memory irrespective of the heating rate. To clarify the origin of the $\gamma$ memory, we focused on the reversely transformed $\gamma$ formed adjacent to the $\theta$ and directly observed the orientation relationships (ORs) using the in-situ EBSD. A crystallographic analysis on the between neighboring ferrites $(\alpha), \theta$, and $\gamma$ revealed the existence of Kurdjumov-Sachs OR between $\gamma$ and two $\alpha(\alpha 1$ and $\alpha 2)$, Isaichev OR between $\alpha$ and $\theta$, and Pitsch OR between $\theta$ and $\gamma$. In the all possible combinations, the reversely transformed $\gamma$ satisfying the $\mathrm{K}-\mathrm{S}$ OR for two $\alpha$ variants was limited to four variants. The $\theta$ variant satisfying the Isaichev OR for $\alpha 1$ and $\alpha 2$ was limited to one variant, which was close to one of the four variants by Pitsch OR, which suggests the $\gamma$ memory is due to these variant restrictions among $\alpha-\theta-\gamma$.
\end{abstract}


Keywords: Transformation, Grain refinement, Orientation relationship, Ferritic steels, EBSD, Crystallographic orientation

* Corresponding Author: E-mail: genki@eng.hokudai.ac.jp; Tel.: +81-11-706-6345 


\section{Introduction}

To improve the fuel efficiency in automobiles, weight reduction of automobile parts, including suspension components like coil springs and leaf springs, is required. To reduce the weight of spring steels, improvement of their mechanical strength and toughness is essential. Among various strategies available such as transformation induced plasticity (TRIP) [1-5] and ausforming[6], grain refinement of austenite $(\gamma)$ is one of the most effective methods of improving the mechanical strength and toughness of steels [7], and can be achieved via various methods, such as cold rolling followed by annealing[8], accumulative roll-bonding[9, 10], cyclic heat treatment[11, 12], and micro alloying[13]. In steel production, a reverse transformation from martensite $\left(\alpha^{\prime}\right)$ to $\gamma$ is often applied for the grain refinement of low-alloy steels [14]. However, when martensite or bainite steels are heated above the $A_{c 3}$ temperature, coarse $\gamma$ grains having the same shape and size as those of the prior $\gamma$ grains are sometimes formed. This phenomenon is called the " $\gamma$ memory effect" $[5,15,16]$. To achieve $\gamma$ grain refinement, this effect is undesirable. Therefore, understanding the mechanism of the $\gamma$ memory effect is important to control the grain structure of the reversely transformed $\gamma$.

According to previous studies [14, 16-20], two different types of reversely transformed $\gamma$ grains exist: acicular $\gamma$ and globular $\gamma$. The acicular $\gamma$ grains have a fine needle-shaped structure, which mainly nucleate and grow along the lath boundary of martensite. These acicular $\gamma$ grains have a unique crystal orientation based on the Kurdjumov-Sachs (K-S) orientation relationship (OR) ( (111) fcc// (011) bcc, $[\overline{1} 01] \mathrm{fcc} / /[\overline{1} \overline{1} 1] \mathrm{bcc})$. Therefore, when the reverse transformation is completed, they coalesce, becoming a coarse $\gamma$ structure same as the prior $\gamma$ structure. Thus, the formation of acicular $\gamma$ grains induces the $\gamma$ memory effect. In contrast, the globular $\gamma$ grains frequently nucleate at the prior $\gamma$ grain boundary and at the martensite packet and block boundaries. Unlike the acicular $\gamma$ grains, the globular $\gamma$ grains formed in a single prior $\gamma$ grain have multiple different crystal orientations, resulting in $\gamma$ grain refinement.

It is known that the heating rate greatly affects the occurrence of the $\gamma$ memory effect 
$[14,20,21]$. It is reported that an extremely high heating rate induces the martensitic diffusionless transformation and it results in $\gamma$ memory effect. On the other hand, when the reverse transformation occurs in a diffusion-controlled manner, relatively rapid heating enhances the formation of globular $\gamma$ grains $[14,16,22]$. To understand the $\gamma$ memory effect at different heating rates, several mechanisms have been proposed: (1) martensitic diffusionless transformation (shear reversion mechanism) [22, 23], (2) growth of slightly retained $\gamma$ (retained $\gamma$ mechanism) $[16,17]$, and (3) variant restriction by crystallographic ORs (variant restriction mechanism). As for the variant restriction mechanism, Watanabe proposed the variant restrictions among ferrite $(\alpha)$-cementite $(\theta)$ $\gamma[24]$ and Nakada reported that internal stress plays an important role in determining the $\gamma$ variant [25]. Recently, it has been reported that dual orientation related to two parent grains have successfully reproduced the experimental texture of martensite [26]. Although the occurrence condition of the $\gamma$ memory effect have been clarified in these studies, the origin of the $\gamma$ memory effect in low carbon steel remains unclear because of the difficulty in direct observation of reverse transformation at high temperature.

The in-situ EBSD technique with a heating stage-equipped scanning electron microscope (SEM) has been applied to observe the reverse transformation of $\gamma$ from martensite directly $[27,28]$. This technique has been employed for observing the in-situ reverse transformation in Fe-0.36C-0.22Si-0.79Mn-3.04Cr alloy [18, 19], Fe-0.2C-1.5Si$1.5 \mathrm{Mn}$ alloy [29], and $\mathrm{Fe}-0.0043 \mathrm{C}-28.7 \mathrm{Ni}-0.86 \mathrm{Mn}$ alloy [30]. In addition, the development of the computation program for reconstruction of prior $\gamma$ orientations based on the measured martensite orientations [31-34] has realized the further investigation of the reversely transformed $\gamma$. Using this reconstruction program, the nucleation sites and ORs of acicular $\gamma$ and globular $\gamma$ grains in tempered martensite of Fe-0.3C-1.5Si-2Mn alloys (mass\%) were analyzed, where the ORs between $\gamma$ and $\theta$ were discussed [35]. These techniques are quite powerful for detailed analysis of reverse transformation.

Therefore, in this study, the effect of the heating rate on the evolution of $\gamma$ memory effect during reverse transformation from martensite to $\gamma$ was studied using in-situ EBSD 
at high temperatures. We focused on the JIS SUP12 spring steel (Fe-0.55C-1.5Si-0.8Mn$0.7 \mathrm{Cr}$ alloy) (in mass $\%$ ), in which the carbide precipitates as the $\theta$ phase. Our first challenge in this study was the direct observation of reverse transformation at different heating rates. Subsequently, we directly observed the generation of $\gamma$ reversely transformed adjacent to $\theta$ and two agrains, and analyzed its ORs. Based on the K-S OR, the variant restriction among $\alpha-\theta-\gamma$ was investigated. Through the systematic calculation of all possible variant combinations and comparison with the direct observation results, we have successfully proposed the variant restriction mechanisms among $\alpha-\theta-\gamma$ to explain why the crystal orientation of the reversely transformed $\gamma$ is restricted to only one variant which is similar to the prior $\gamma$ as per the $\gamma$ memory effect. 


\section{Experimental procedures}

The sample used in this study was a micro-alloyed JIS SUP-12 spring steel (Fe$0.55 \mathrm{C}-1.55 \mathrm{Si}-0.8 \mathrm{Mn}-0.001 \mathrm{~S}-0.8 \mathrm{Cr}-0.025 \mathrm{Al}-0.003 \mathrm{Ti}-0.003 \mathrm{~N}$ alloy) (in mass\%). The steel was hot-rolled at $1100-1200{ }^{\circ} \mathrm{C}$ into a rod with a diameter of $15 \mathrm{~mm}$. The rod was solution-treated at $1300{ }^{\circ} \mathrm{C}$ for $1 \mathrm{~h}$ followed by water-quenching. Some of the sample solution-treated at $1300{ }^{\circ} \mathrm{C}$ was tempered at $700{ }^{\circ} \mathrm{C}$ for $24 \mathrm{~h}$ and then furnace-cooled to obtain the precipitation of $\theta$ particles. The spring steel with and without the tempering at $700{ }^{\circ} \mathrm{C}$ were cut into dimensions of $5 \mathrm{~mm} \times 7 \mathrm{~mm} \times 0.5 \mathrm{~mm}$, setting the longitudinal direction in the hot rolling direction. The samples were mechanically polished with SiC papers and aluminum powders $(0.3-1 \mu \mathrm{m})$, and Ar-ion milled using an ion milling system (IM4000, Hitachi High-Technologies Corp.) to remove the layer damaged by mechanical polishing. An in-situ SEM-EBSD analysis was performed using a heating stage (HSEA1000, TSL solutions K.K.)-equipped field emission (FE)-SEM (JSM-7900F, JEOL Ltd.). The orientation maps were acquired using the EBSD with an acceleration voltage of 15 $\mathrm{kV}$ and a probe current of $80 \mathrm{nA}$. Figure 1 shows the heat patterns used for the in-situ EBSD measurements, measured by thermocouples spot-welded at the surface of the sample. To investigate the effects of the heating rate, we used two acquisition methods: stepwise and continuous measurements. In the stepwise measurements, the analysis area was $300 \mu \mathrm{m} \times 300 \mu \mathrm{m}$, and the step size was $1.5 \mu \mathrm{m}$. In the continuous measurements, on the other hand, the analysis area was $100 \mu \mathrm{m} \times 100 \mu \mathrm{m}$, and the step size was $1 \mu \mathrm{m}$. The obtained EBSD patterns were analyzed using a software (OIM Analysis, TSL solutions K.K.). For microstructural observation, the solution-treated sample was heated at $500{ }^{\circ} \mathrm{C}$ for 48 hours, sectioned in the transverse direction, mechanically polished, and etched by a 4 mass $\%$ picric acid solution at $50{ }^{\circ} \mathrm{C}$. The microstructure was observed using scanning electron microscopy (SEM, ProX, Phenom-World B.V.). The thermodynamic calculation was performed using the Thermo-Calc software version 2019a, with the TCFE9 database[36].

The precipitated cementite $(\theta)$ in the sample tempered at $700{ }^{\circ} \mathrm{C}$ for $24 \mathrm{~h}$ was 
investigated using a transmission electron microscope (TEM, JEM-2010F, JEOL Ltd.). The samples were polished and then Ar-ion milled with $5 \mathrm{kV}$ using a precision ion polishing system (PIPS, model 691, Gatan Inc.) and used for the TEM analysis. The extraction replica method was also applied for the precipitation analysis. The sample was electrically etched in a $10 \%$ acetylacetone solution $(10 \%$ acetylacetone, $1 \%$ tetramethylammonium chloride, and methanol), and the precipitates were then transferred from the surface to the replica film. Carbon was deposited onto the replica film, and the film was dissolved in acetone. The peeled carbon sheet with the precipitates was captured by a copper grid. The precipitates on the carbon film were observed using the TEM.
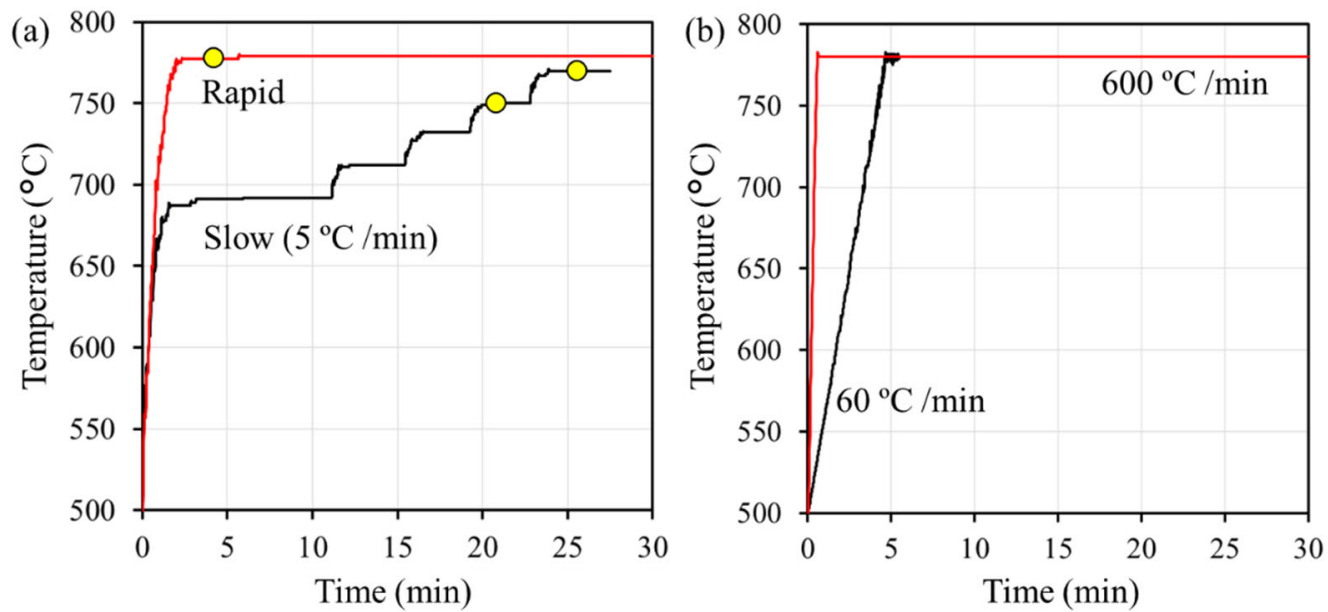

Figure 1 Heat patterns for in-situ EBSD measurements: (a) Stepwise measurement at different heating rates. The circles indicate the EBSD measurement points. (b) Continuous measurement at 600 and $60{ }^{\circ} \mathrm{C} / \mathrm{min}$. The EBSD measurement was repeated continuously during heating.

\section{Results and discussion}

\subsection{Effects of heating rate}

To investigate the effects of heating rate, the sample solution-treated at $1300{ }^{\circ} \mathrm{C}$ without any further heat treatment was in-situ observed using SEM-EBSD during reheating. Figure 2 shows the volume fraction of each phase existing in the alloy, 
determined from the thermodynamic calculation. The calculated $A_{c 1}$ and $A_{c 3}$ temperatures are 745.1 and $787.1{ }^{\circ} \mathrm{C}$, respectively. At $780{ }^{\circ} \mathrm{C}$, the volume fractions of the $\gamma$ and $\alpha$ phases are $95 \%$ and $5 \%$, respectively. Based on the calculated result, the maximum reheating temperature was set to $770-780{ }^{\circ} \mathrm{C}$, which is around the calculated $\mathrm{A}_{\mathrm{c} 3}$ temperature. Figure 3 shows the SEM image of $\gamma$ grain structure obtained from the sample solutiontreated at $1300{ }^{\circ} \mathrm{C}$ and then quenched without any further heat treatment. The $\gamma$ grain size ranged from 20 to $300 \mu \mathrm{m}$. At $1300{ }^{\circ} \mathrm{C}$, all the precipitates, such as AlN, were dissolved in $\gamma$ iron and $\gamma$ grain coarsening occurred. Figure 4 shows the SEM-EBSD images obtained by stepwise measurement with slow and rapid heating patterns (shown in Fig. 1(a)). At room temperature, the sample has a martensite structure without retained $\gamma$, and the prior $\gamma$ grain boundary can be seen (Figs. 4(a, e)). These prior $\gamma$ grain boundaries correspond to the initial microstructure shown in Fig.3. Figure 5 (a) shows the selected pole figures corresponding to each area shown in Fig.4(a). These characteristic patterns depend on the orientation of the prior $\gamma$ and the OR between the $\gamma$ and martensite, indicating that these selected areas are from single prior $\gamma$ grains. Figure 4 (b) shows the $\gamma$ orientation map at $750{ }^{\circ} \mathrm{C}$ for the same area shown in Fig. 4 (a). Figure 4 (c) shows the $\gamma$ orientation map at $770{ }^{\circ} \mathrm{C}$, indicating that slow heating leads to a coarse $\gamma$ structure. Figure 5 (b) shows the pole figures from the selected area shown in Fig. 4 (c), in which each reversely transformed $\gamma$ has K-S OR with the mother phase of martensite as shown in Fig.5 (a), which also has K-S OR with the prior $\gamma$. From Fig.5 (a) and (b), the reversely transformed $\gamma$ has the same shape and orientation as those of the prior $\gamma$ grains, this is known as the " $\gamma$ memory effect" [16].

In contrast, when the sample is rapidly heated to $780^{\circ} \mathrm{C}$, the reverse transformation leads to a fine $\gamma$ grain structure, as shown in Fig. 4(f). This confirms that the heating rate strongly affects the $\gamma$ grain structure and the rapid heating is significantly effective for grain refinement. In Fig. 4(c), fine grains are also formed near the prior $\gamma$ grain boundaries, as indicated by yellow arrows. The crystal orientations of these particles are not related to the mother phase of martensite. Figure 4(d) shows the Kernel average misorientation 
(KAM) maps corresponding to Fig. 4(c), wherein the KAM value is associated with the existence of strain. The coarse $\gamma$ grains generated by the $\gamma$ memory effect have relatively high KAM values, whereas the fine $\gamma$ grains (yellow arrows) have lower KAM values. As mentioned in the introduction section, two types of reversely transformed $\gamma$ exist: acicular $\gamma$ and globular $\gamma$. The coarse $\gamma$ grains with a high KAM value correspond to acicular $\gamma$ grains, whereas the fine $\gamma$ grains with a low KAM value correspond to globular $\gamma$ grains. The acicular $\gamma$ grains have a unique crystal orientation based on the K-S OR with the mother phase of martensite, and they nucleate along the lath boundary of martensite. Because the martensite lath boundary exhibits a misorientation of a few degrees, the reversely transformed coarse $\gamma$ grains comprising small acicular $\gamma$ grains exhibit misorientations, resulting in a high KAM value [18]. In contrast, the globular $\gamma$ grains mainly nucleate at the prior austenite grain boundaries and at the martensite packet and block boundaries. The globular $\gamma$ grains grow without plastic strain introduction, resulting in a low KAM value. In the case of rapid heating, fine globular $\gamma$ grains are mainly formed, as shown in Fig. 4(f), and the corresponding KAM values (Fig. 4(g)) are lower than those in the slow heating case. Because the prior austenite grain boundaries can be a nucleation site of globular $\gamma$, the finer $\gamma$ grains are generated around grain boundaries. In the case of rapid heating, KAM values are relatively low compared to that of slow heating. 


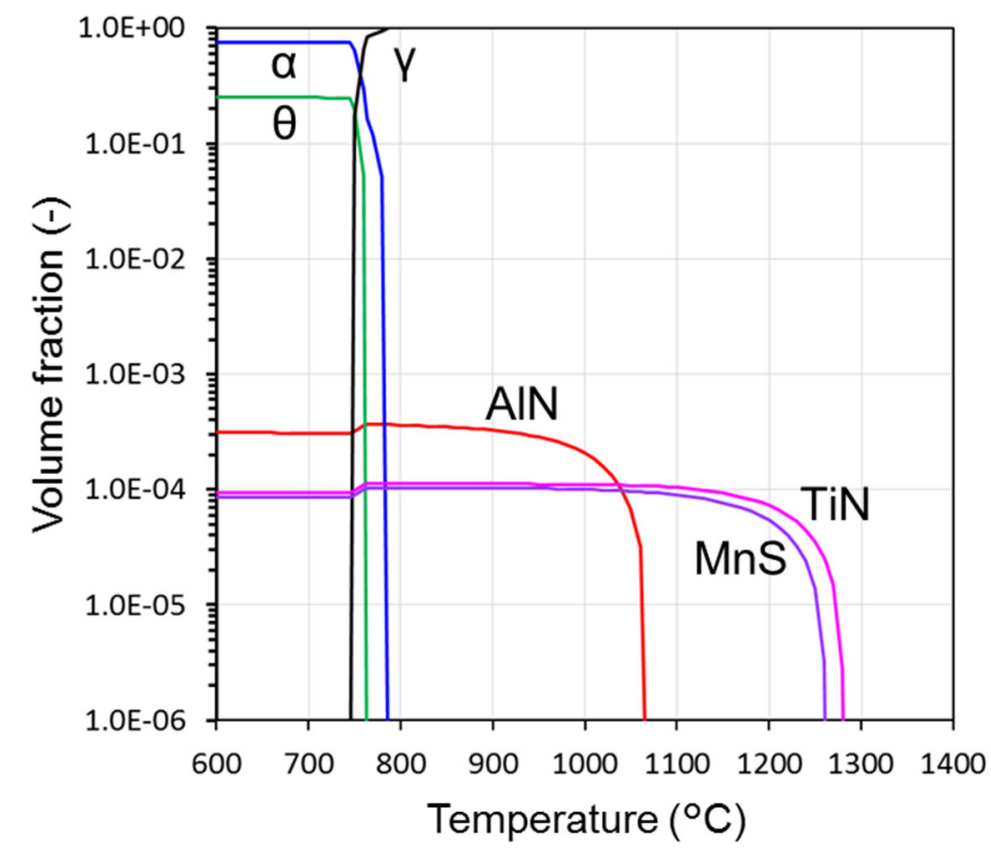

Figure 2 Volume fraction of each phase, determined by thermodynamic calculations.

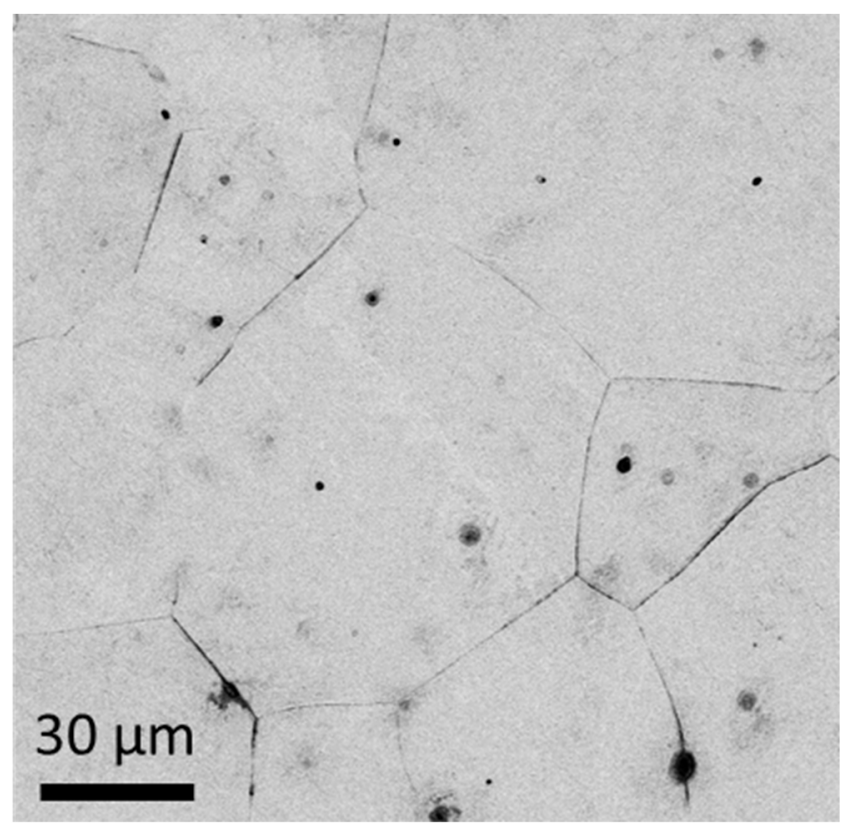

Figure 3 SEM image of $\gamma$ grain structure obtained from the sample solution-treated at $1300{ }^{\circ} \mathrm{C}$. 

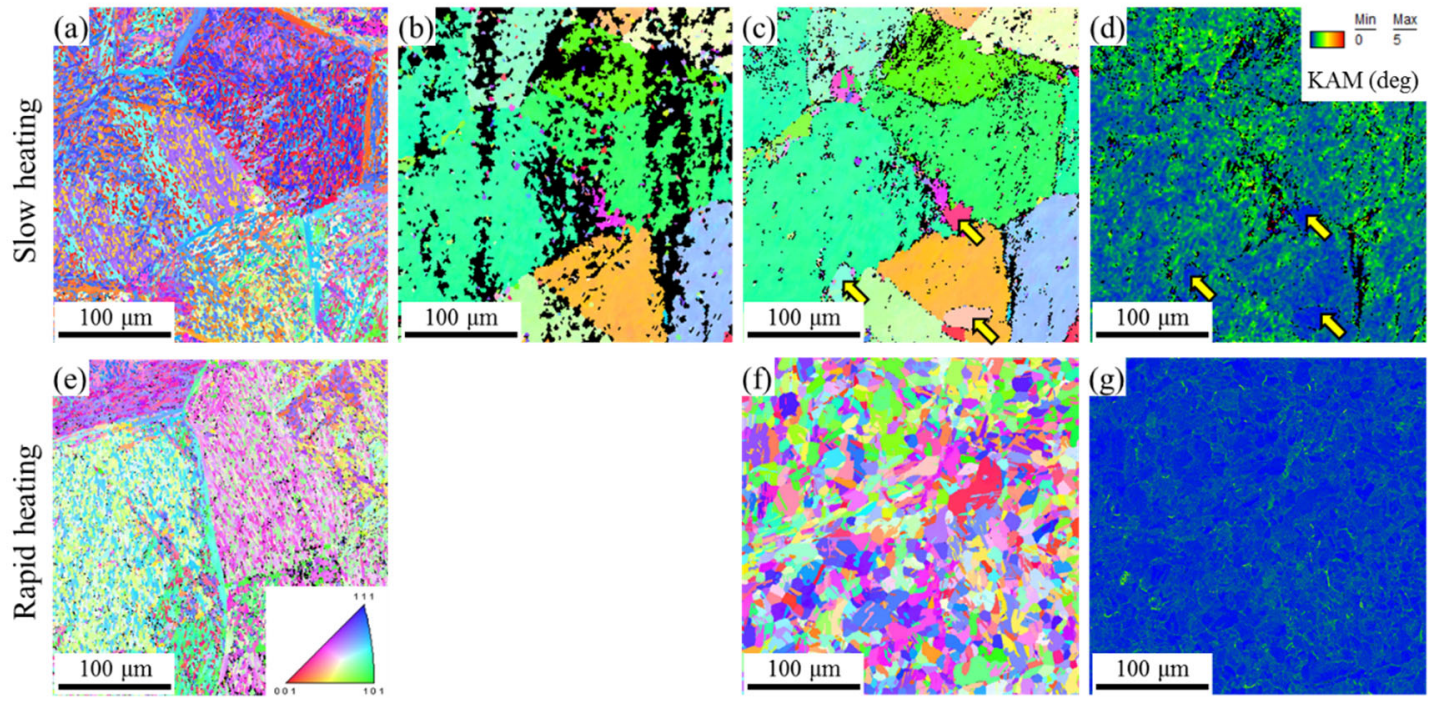

Figure 4 SEM-EBSD images obtained by stepwise measurement with slow heating (a-d) and rapid heating (e-g). Images (a) and (e) show the $\alpha$ orientation maps at room temperature, and (b), (c) and (f) show the $\gamma$ orientation maps at temperatures of 750, 770, and $780{ }^{\circ} \mathrm{C}$ acquired for the same area as that shown in (a) and (e). Images (d) and (g) show the Kernel average misorientation (KAM) maps of $\gamma$ corresponding to (c) and (f), respectively.

(a) $\alpha$ orientation maps at room temperature

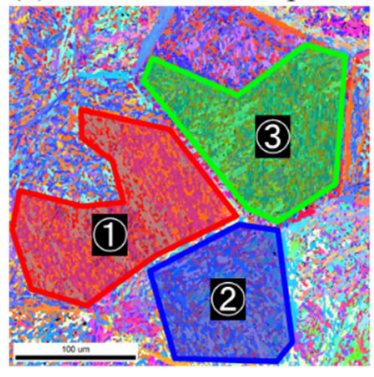

(b) $\gamma$ orientation maps at $770^{\circ} \mathrm{C}$

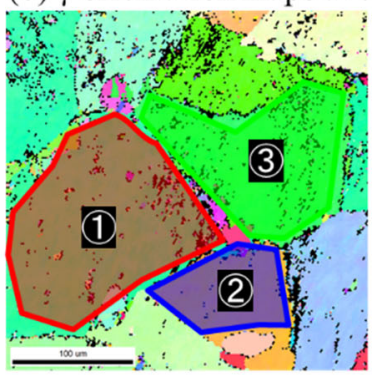

(1)

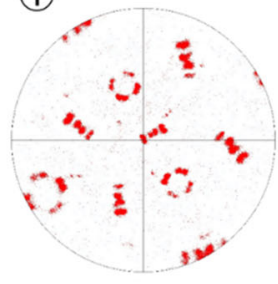

(2)
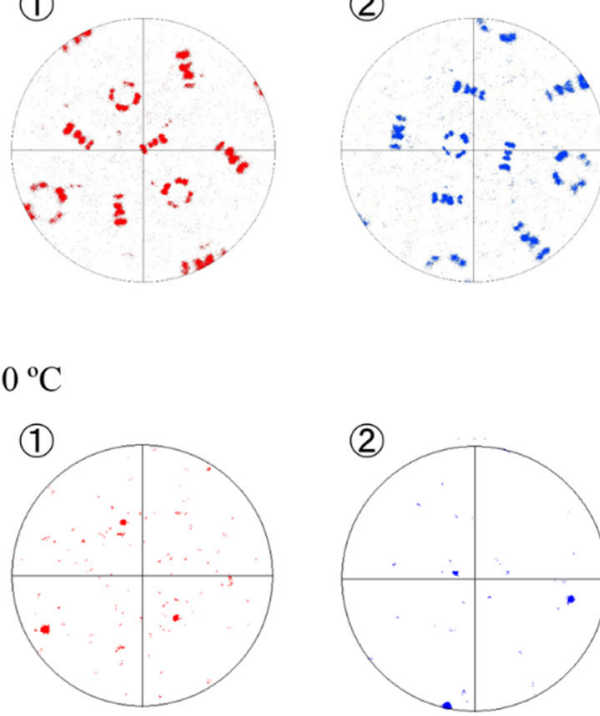

(2)

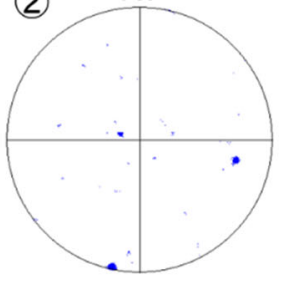

(3)

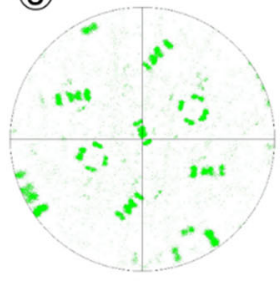

(3)

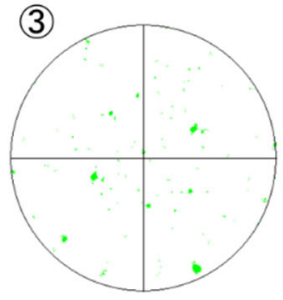

Figure 5 SEM-EBSD images and selected pole figures corresponding to each area. 
Images (a) show the $\alpha$ orientation maps at room temperature corresponding to Fig.4 (a) and selected pole figures. Images (b) show the $\gamma$ orientation maps at $770{ }^{\circ} \mathrm{C}$ corresponding to Fig.4 (c) and selected pole figures.

In the case of stepwise measurement at a constant temperatures, the dynamic transition during the reverse transformation cannot be clearly observed. Therefore, we performed a continuous measurement during heating. Figure 1(b) shows the thermal histories at heating rates of 60 and $600{ }^{\circ} \mathrm{C} / \mathrm{min}$. The EBSD maps were acquired continuously from 500 to $780{ }^{\circ} \mathrm{C}$. Figures 6(a)-(c) show the EBSD maps obtained during heating at $60^{\circ} \mathrm{C} / \mathrm{min}$ with different heating durations. Figure $6($ a) shows the $\gamma$ orientation map just after the completion of the reverse transformation. There are large yellow and blue grains in the map, as indicated by "Y" and "B," respectively. These coarse grains have a K-S OR with the mother phase of martensite. Thus, the formation of the coarse $\gamma$ grains formed due to the $\gamma$ memory effect. On the other hand, there are small globular $\gamma$ grains with random orientations observed in Fig. 6(a). When the sample was kept at $780{ }^{\circ} \mathrm{C}$, these small globular $\gamma$ grains grew, as shown in Fig. $6(\mathrm{~b})$, during the time interval of 520-560 s. Although the size of $\gamma$ grains induced by the $\gamma$ memory effect was initially large, these grains did not grow, being encroached by the surrounding fine globular $\gamma$ grains. After $1160 \mathrm{~s}$, as shown in Fig. 6(c), the initial $\gamma$ grains labeled "Y" and "B" almost disappeared owing to the grain growth of the surrounding globular $\gamma$ grains. This phenomenon can be explained by the difference in KAM value. KAM value indicates the level of the strain in the grain, and as shown in Fig.4 (d), the large $\gamma$ grains formed by the $\gamma$ memory effect has a high level of strain. Therefore, these large $\gamma$ grains are relatively unstable. In contrast, as shown in Fig.4 (g), the globular $\gamma$ grains have a lower KAM value, which means they are more stable. Thus, the stable globular $\gamma$ grains encroached the unstable large grains, as in the case of recrystallization. Figure 6(d) shows the $\gamma$ orientation map during heating from 500 to $780{ }^{\circ} \mathrm{C}$ at $600{ }^{\circ} \mathrm{C} / \mathrm{min}$. Because the EBSD scan starts from the top of the image, the sample temperature is different at each 
measuring point. The center of this image corresponds to $780{ }^{\circ} \mathrm{C}$. Because $\gamma$ grains did not nucleate below transformation temperature, the upper region of Fig. 6(d) shows by black due to absence of $\gamma$. After the temperature reached $780{ }^{\circ} \mathrm{C}$, the fine $\gamma$ grains were uniformly formed without the $\gamma$ memory effect, and the grain growth during a period of about $600 \mathrm{~s}$ from Figs. $6(\mathrm{e})$ to (f) is not significant. In the case of $600{ }^{\circ} \mathrm{C} / \mathrm{min}$, fine globular $\gamma$ grains are mainly formed, and the grain growth is relatively suppressed because these grains have similar KAM values. This result also shows that the heating rate affects the frequency of the $\gamma$ memory effect and that rapid heating is effective in suppressing this effect.
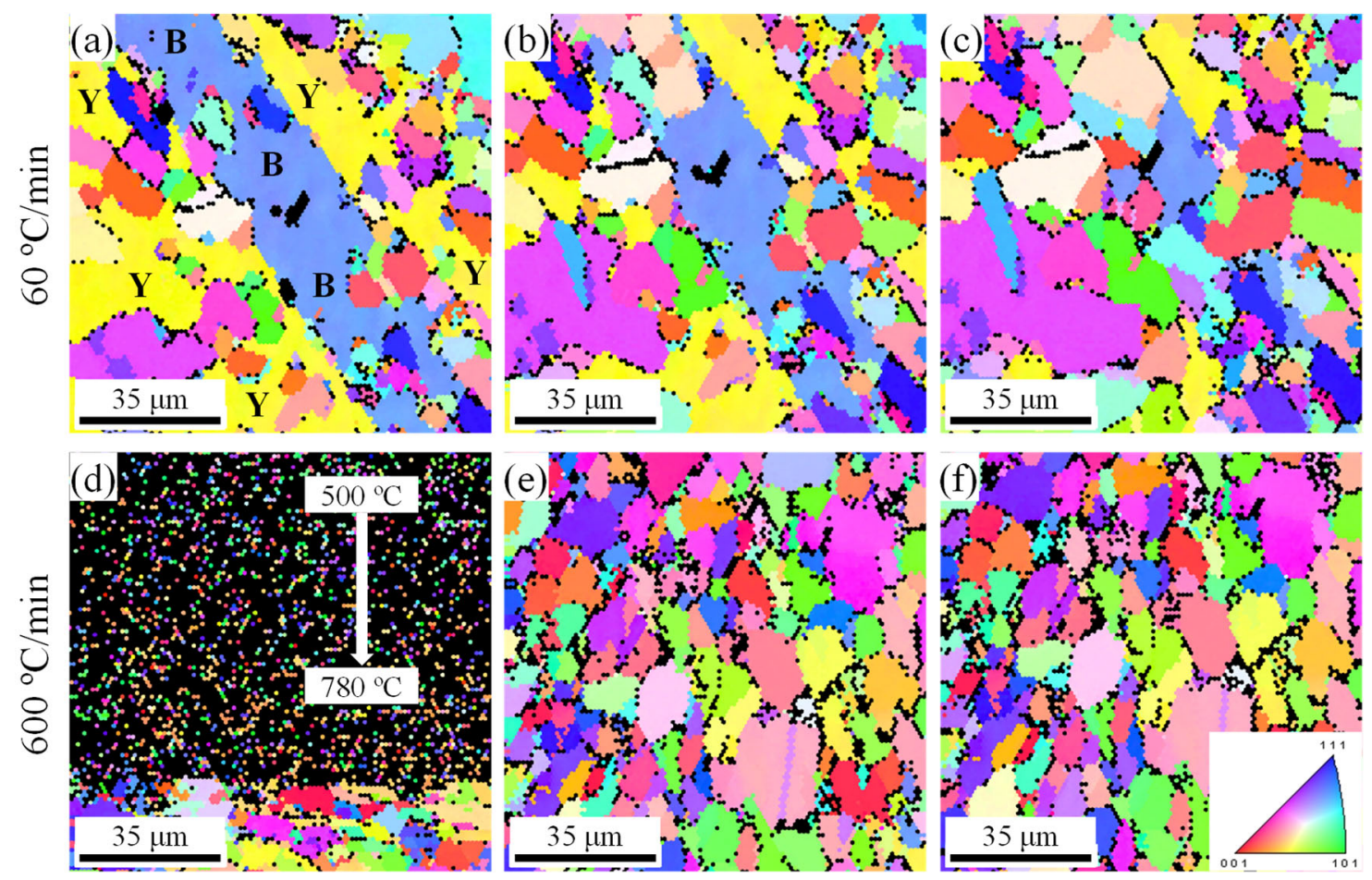

Figure 6 SEM-EBSD images obtained by continuous measurement at heating rates of $60{ }^{\circ} \mathrm{C} / \mathrm{min}(\mathrm{a}-\mathrm{c})$ and $600^{\circ} \mathrm{C} / \mathrm{min}$ (d-f) with temperatures and heating durations of (a) $772-$ $780{ }^{\circ} \mathrm{C} ; 320-360 \mathrm{~s},(\mathrm{~b}) 780{ }^{\circ} \mathrm{C} ; 520-560 \mathrm{~s}$, (c) $780{ }^{\circ} \mathrm{C} ; 1160-1200 \mathrm{~s}$, (d) 500-780 ${ }^{\circ} \mathrm{C} ; 0$ $40 \mathrm{~s}$, (e) $780{ }^{\circ} \mathrm{C} ; 520-560 \mathrm{~s}$, (f) $780{ }^{\circ} \mathrm{C} ; 1160-1200 \mathrm{~s}$.

Figure 7 schematically summarizes the reverse transformation behaviors at different 
heating rates. With the increase in heating rate, the formation of globular $\gamma$ grains is enhanced, which agrees with the results obtained in the previous experiments. Grange reported that in the reverse transformation at a high heating rate lead to fine $\gamma$ grain size compared to that obtained at a low heating rate [21]. Matsuda and Okamura[14], and Han and Lee[22] reported that rapid heating enhanced the formation of globular $\gamma$ grains, resulting in $\gamma$ grain refinement. Although the surface effect and element evaporation can occur during in-situ SEM-EBSD experiments, our present results are consistent with their previous experimental results. Regarding the origin of the $\gamma$ memory effect, three different mechanisms have been proposed: (1) shear reversion mechanism [22, 23], (2) retained austenite mechanism [16, 17], and (3) variant restriction mechanism [24]. Watanabe and Kinitake[24] proposed a mechanism for the $\gamma$ memory effect, in which the crystal orientation of reversely transformed $\gamma$ can be limited by the ORs of $\theta-\alpha, \gamma-\alpha$, and $\theta-\gamma$. Such ORs were confirmed in a recent experimental study [35]. Note that the heating rate used in this study is considered to be not too high to induce diffusionless transformation. In addition, the retained $\gamma$ was not detectable in our sample. Thus, the variant restriction owing to the formation of precipitated $\theta$ could most likely be the reason for the $\gamma$ memory effect observed in our samples. According to the thermodynamic phase diagram calculations (Fig. 2), the precipitates of $\theta, \mathrm{AlN}$, TiN and $\mathrm{MnS}$ can exist at $700{ }^{\circ} \mathrm{C}$, in which $\mathrm{M}_{7} \mathrm{C}_{3}$ and $\mathrm{M}_{23} \mathrm{C}_{6}$ are not stable. Volume fractions of these precipitates are $25 \%$ of $\theta$, $0.03 \%$ of AlN, $0.0094 \%$ of TiN, and $0.0085 \%$ of MnS. Although effects of AlN, TiN, and $\mathrm{MnS}$ on $\gamma$ memory effect are not clear, we considered the effects, if any, must be negligibly small because of their small volume fractions. From these reasons, we focused on the effect of $\theta$ on $\gamma$ memory effect. It is reported that due to tempering after quenching the $\theta$ particles precipitate on high-angle boundaries (grain boundary of prior austenite, block and packet boundaries of martensite) as well as within laths and at low-angle boundaries (lath boundaries) [37]. As heating rate increases, $\theta$ precipitates become finer and more uniform. Difference in $\theta$ morphology can affect the $\gamma$ memory effect. It is considered that slow heating enhance the growth of $\theta$. When reversely-transformed $\gamma$ is 
formed adjacent to the coarse $\theta$, variant restriction of $\alpha, \theta$ and $\gamma$ might induce the $\gamma$ memory effect. To check the validity of this hypothesis, we investigated the existence ORs among $\gamma, \alpha$ and $\theta$.

(a) Initial martensite

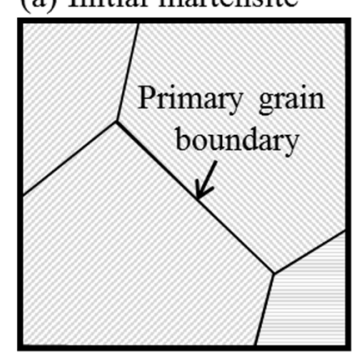

(b) $5^{\circ} \mathrm{C} / \mathrm{min}$

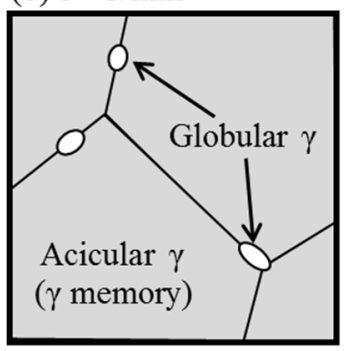

(c) $60^{\circ} \mathrm{C} / \mathrm{min}$

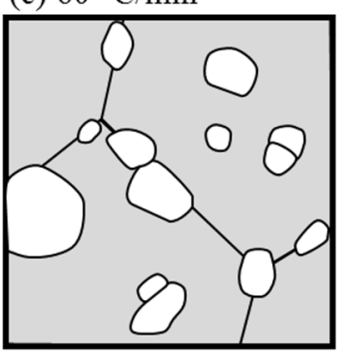

(d) $600^{\circ} \mathrm{C} / \mathrm{min}$

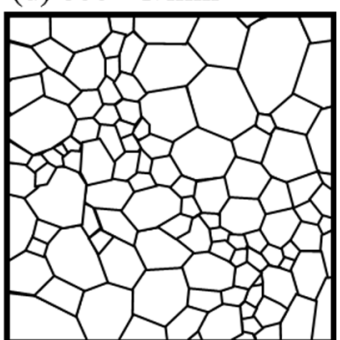

Figure 7 Schematics of reverse transformations at different heating rates: (a) Initial structure of martensite. Structures after reverse transformation at heating rates of (b) $5{ }^{\circ} \mathrm{C} / \mathrm{min}$, (c) $60{ }^{\circ} \mathrm{C} / \mathrm{min}$, and (d) $600{ }^{\circ} \mathrm{C} / \mathrm{min}$.

\subsection{Effect of cementite precipitation}

The sample solution-treated at $1300{ }^{\circ} \mathrm{C}$ was water-quenched and then tempered at $700{ }^{\circ} \mathrm{C}$ for $24 \mathrm{~h}$ and then cooled in a furnace to precipitate $\theta$. Figure 8 (a) shows TEM image of $\theta$ in the steel, and the white arrow indicates $\theta$. Figure $8(b)$ shows a highresolution TEM image of $\theta$ shown in Fig. 8(a). Figure 8(c) shows the corresponding fast Fourier transform image of the $\theta$ precipitate, indicating that the precipitate is single crystalline and has a crystal structure of $\theta$. Figure $8(d)$ shows TEM image of the $\theta$ particles obtained using the extraction replica method. The energy dispersive X-ray spectrometry (EDS) analysis results revealed that these $\theta$ particles mainly consisted of the $\mathrm{Fe}, \mathrm{Cr}$ and Mn. 

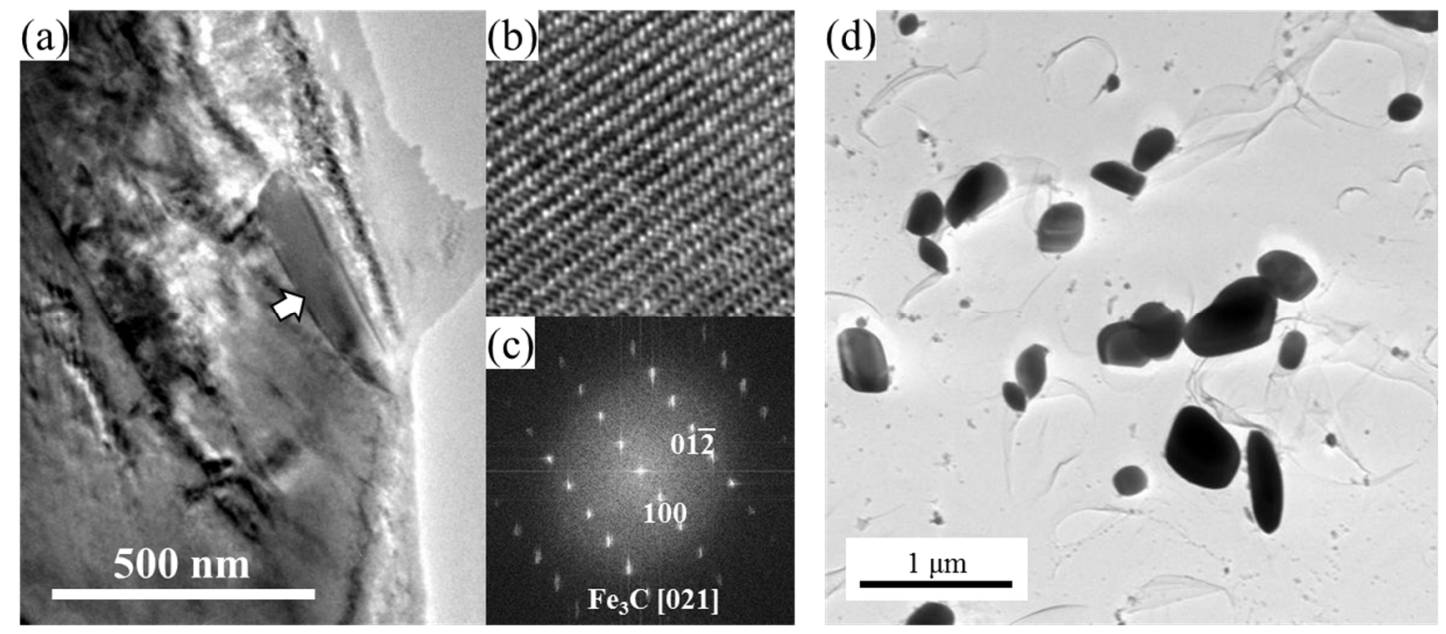

Figure 8 TEM observations of cementite in the sample tempered at $700{ }^{\circ} \mathrm{C}$ for $24 \mathrm{~h}$. (a) TEM image of cementite in the steel, (b) high-resolution TEM image, and (c) fast Fourier transform image of (b), and (d) TEM image of cementite particles collected using the extraction replica method.

Figure 9 shows the SEM-EBSD images of the sample tempered at $700{ }^{\circ} \mathrm{C}$ for $24 \mathrm{~h}$. Compared to the sample without tempering, thickness of lath increased, as shown in Fig.9 (a). Completion of the reverse transformation required heating up to around $860{ }^{\circ} \mathrm{C}$, which is higher than $780{ }^{\circ} \mathrm{C}$ for the sample without tempering. This increased transformation temperature might be related to the formation of coarse $\theta$. It is reported that the thickness of lath increases with the increase in heating duration during tempering, which also results in coarsening of $\theta[38]$. Because the dissolution of such coarse $\theta$ is slow, the completion of the reverse transformation might be delayed. Before reheating, there were three prior $\gamma$ grains in the observation area as understood from $\alpha$ orientation map in Fig. 9(a). When the sample was heated rapidly, the $\gamma$ memory effect are seen in Fig. 9(b), indicated by I, II, and III, although globular $\gamma$ grains were partially formed. This result is in contrast with the case of the sample without tempering, where the rapid heating refined the $\gamma$ grains (Fig. 4(f)). In addition, the slow heating of the tempered sample also induced the $\gamma$ memory effect. This result suggests that the precipitation of coarse $\theta$ induces $\gamma$ memory effect in both rapid and slow heating. 

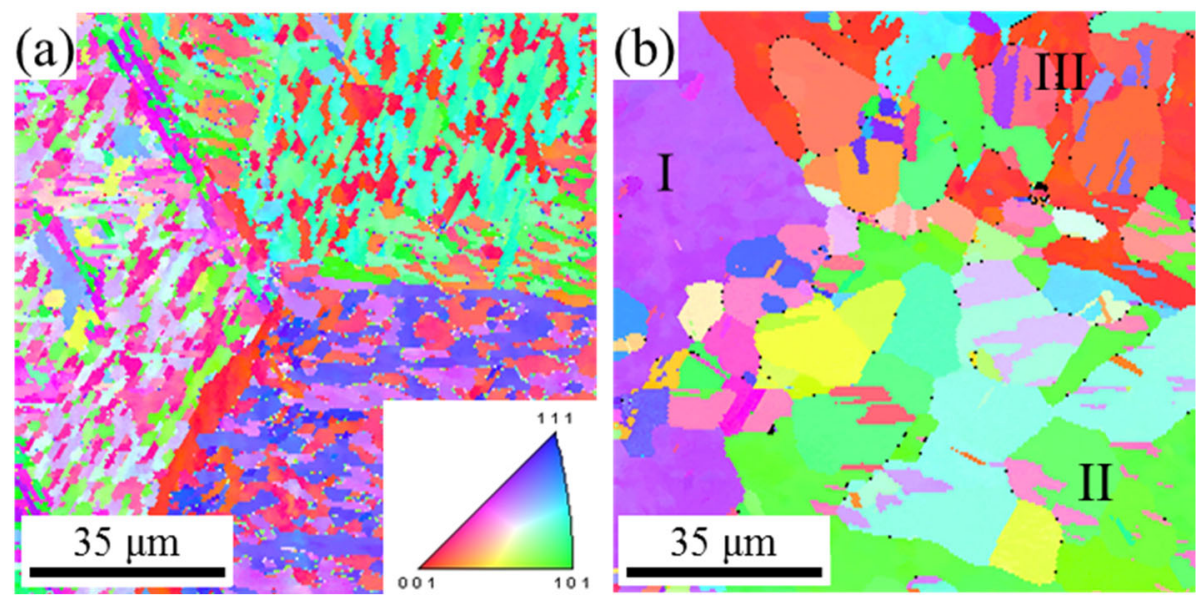

Figure 9 (a) SEM-EBSD images of the sample tempered at $700{ }^{\circ} \mathrm{C}$ for $24 \mathrm{~h}$ with rapid heating. (a) $\alpha$ orientation map at room temperature, and (b) $\gamma$ orientation maps at a temperature of $860^{\circ} \mathrm{C}$ after rapid heating, obtained in the same area as that shown in (a).

To investigate the ORs between $\theta-\alpha$ and $\theta-\gamma$, an in-situ SEM-EBSD observation was conducted with a high magnification. Figure 10(a) shows the SEM-EBSD images of $\alpha$ at room temperature before reheating. The black area corresponds to $\theta$, which formed on a sub-block boundary between $\alpha 1$ and $\alpha 2$ inside a prior $\gamma$ grain. Figure 10(b) shows the SEM-EBSD images at $735{ }^{\circ} \mathrm{C}$. The reversely transformed $\gamma$ developed adjacent to $\theta$. Figures 10 (c)-(f) show the stereographic projections for the ORs of $\alpha 1, \alpha 2, \gamma$, and $\theta$. There exist K-S OR $((111) \gamma / /(011) \alpha,[\overline{1} 01] \gamma / /[\overline{1} 11] \alpha)[24,39]$ between $\gamma-\alpha 1$ and $\gamma-\alpha 2$ (Figs. 10(c) and (d)), Isaichev OR $((011) \alpha / /(031) \theta,[\overline{1} \overline{1} 1] \alpha / /[100] \theta)[40]$ between $\alpha 1$ $\theta$ and $\alpha 2-\theta$ (Fig. 10(e)), and Pitsch OR $((031) \theta / /(111) \gamma,[100] \theta /[\overline{1} 01] \gamma)[41]$ between $\theta$ and $\gamma($ Fig. 10(f)). 

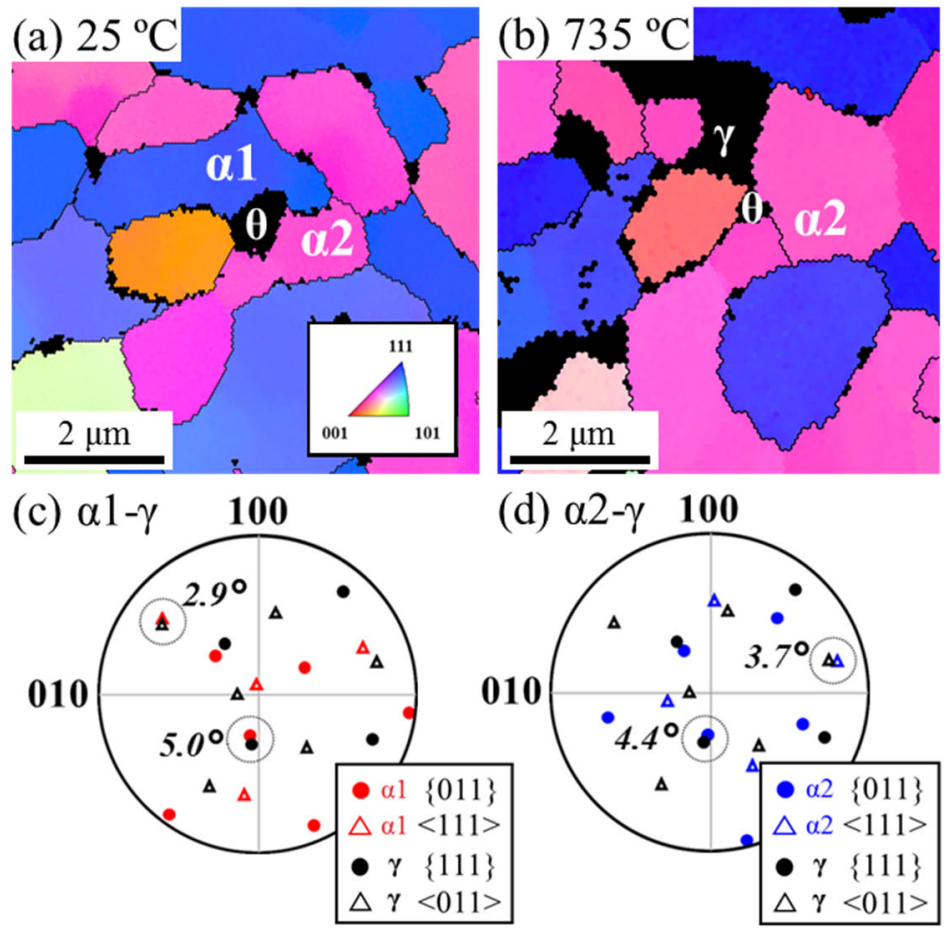

(d) $\alpha 2-\gamma \quad 100$
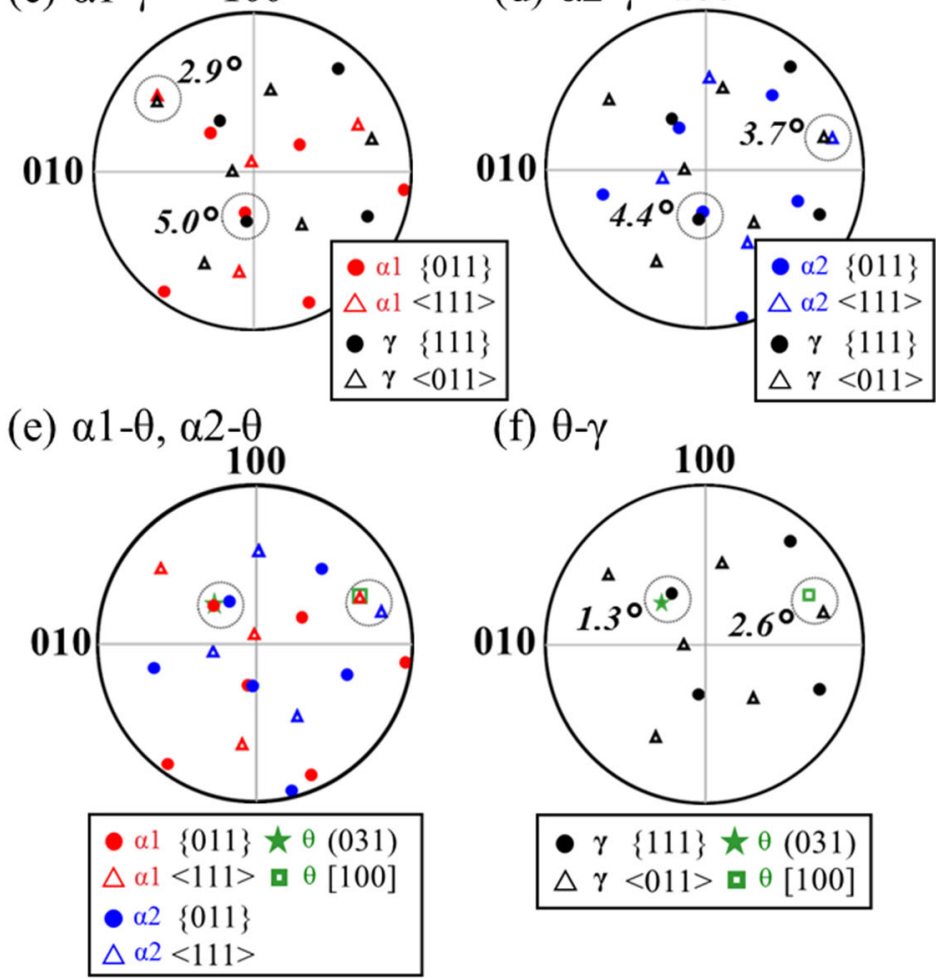

(f) $\theta-\gamma$

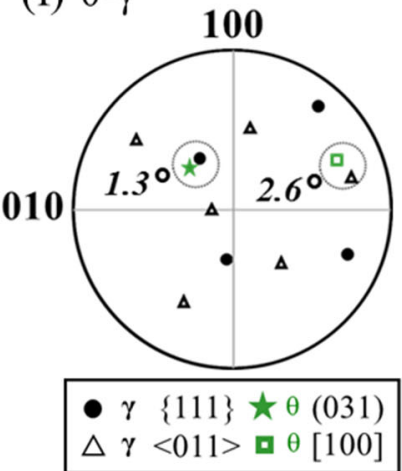

Figure 10 Analysis of ORs of the sample tempered at $700{ }^{\circ} \mathrm{C}$ for $24 \mathrm{~h}$. Enlarged orientation maps of $\alpha, \gamma$, and $\theta$ during reverse transformation at (a) $25^{\circ} \mathrm{C}$ and (b) $735{ }^{\circ} \mathrm{C}$. Corresponding stereographic projections for ORs of (c) $\alpha 1-\gamma$, , d) $\alpha 2-\gamma$, (c) $\alpha 1-\theta$ and $\alpha 2-\theta$, and (d) $\theta-\gamma$. The numbers seen in (c), (d) and (f) indicate the misorientation degrees.

The EBSD-SEM analysis results confirm the existence of ORs between $\theta-\alpha, \alpha-\gamma$, and $\theta-\gamma$. However, they did not explain the origin of the $\gamma$ memory effect yet. It should be clarified why the crystal orientation of the reversely transformed $\gamma$ is restricted to only one variant similar to the prior $\gamma$. Therefore, we analyzed the possible $\gamma$ variant(s) that can 
form from the two $\alpha$ variants ( $\alpha 1$ and $\alpha 2$ observed in in Fig. 10), satisfying the KS, Isaichev and Pitsch ORs simultaneously. Because the raw data obtained from SEM-EBSD are represented using the units of Euler angles $(\phi 1, \Phi$, and $\phi 2)$ and the obtained coordinate system is based on standard axes, such as the transverse direction (TD) and normal direction (ND), the coordinate system was transformed from the standard axes to the measured one of each crystal using the rotating matrix $\mathbf{g}$, as follows.

$$
\mathrm{g}=\left(\begin{array}{ccc}
\cos \phi 2 & -\sin \phi 2 & 0 \\
\sin \phi 2 & \cos \phi 2 & 0 \\
0 & 0 & 1
\end{array}\right)\left(\begin{array}{ccc}
\cos \Phi & 0 & \sin \Phi \\
0 & 1 & 0 \\
\sin \Phi & 0 & \cos \Phi
\end{array}\right)\left(\begin{array}{ccc}
\cos \phi 1 & -\sin \phi 1 & 0 \\
\sin \phi 1 & \cos \phi 1 & 0 \\
0 & 0 & 1
\end{array}\right)
$$

The possible $\gamma$ variants having K-S ORs in the two different $\alpha$ variants of $\alpha 1$ and $\alpha 2, V_{\alpha 1}$ and $\mathrm{V}_{\alpha 2}$, corresponding to Fig. 10, were systematically determined using 24 types of rotating matrices $\mathbf{T}_{\mathbf{K}-\mathrm{S}}[42]$, which represents the $\mathrm{K}-\mathrm{S}$ ORs listed in Table 1. With this rotating matrix, the change in the crystallographic orientation during reverse transformation could be described as follows $[43,44]$.

$$
\mathrm{V}_{\alpha \mathrm{x}}=\mathbf{T}_{\mathbf{K}-\mathbf{S}} \cdot \gamma \mathrm{V}_{\alpha \mathrm{x}}
$$

Here, $\gamma \mathrm{V}_{\alpha \mathrm{x}}$ indicates the variant of $\gamma$ having $\mathrm{K}-\mathrm{S}$ ORs with $\mathrm{V}_{\alpha \mathrm{x}}$. From one $\mathrm{V}_{\alpha \mathrm{x}}, 24$ variants of $\gamma \mathrm{V}_{\alpha x}$ are allowed. Because the reversely transformed $\gamma$ should have $\mathrm{K}-\mathrm{S}$ ORs with both $\mathrm{V}_{\alpha 1}$ and $\mathrm{V}_{\alpha 2}$, the possible $\gamma$ variants following the two conditions are limited. Based on the orientation analysis of all the combinations, four combinations ( $\gamma \mathrm{I}, \gamma \mathrm{II}, \gamma \mathrm{III}$, and $\gamma \mathrm{IV})$ are allowed, as shown in Fig. 11(a). $V_{\alpha 1}$ and $V_{\alpha 2}$ share a unique (011) plane, and the four $\gamma$ variants have significantly small misorientations from the shared $\{011\} \alpha$ planes. Figure 11(b) shows the stereographic projections of the corresponding four $\gamma$ variants, where $\gamma \mathrm{I}$, $\gamma \mathrm{II}, \gamma \mathrm{III}$, and $\gamma \mathrm{IV}$ are $\gamma 4 \mathrm{~V}_{\alpha 1}-\gamma 3 \mathrm{~V}_{\alpha 2}, \gamma 5 \mathrm{~V}_{\alpha 1}-\gamma 18 \mathrm{~V}_{\alpha 2}, \gamma 22 \mathrm{~V}_{\alpha 1}-\gamma 18 \mathrm{~V}_{\alpha 2}$, and $\gamma 23 \mathrm{~V}_{\alpha 1}-\gamma 20 \mathrm{~V}_{\alpha 2}$, respectively. From the analysis of the $\mathrm{K}-\mathrm{S}$ OR, it is found that the reversely transformed $\gamma$ is limited to four variants.

Table $1 \mathrm{~K}-\mathrm{S}$ ORs with 24 variants. 


\begin{tabular}{|c|c|c|}
\hline Variant & Plane parallel & Direction parallel \\
\hline$\gamma 1$ & \multirow{6}{*}{$(111) \gamma / /(011) \alpha$} & {$[\overline{1} 01] \gamma / /[\overline{1} \overline{1} 1] \alpha$} \\
\hline$\gamma 2$ & & {$[\overline{1} 01] \gamma / /[\overline{1} 1 \overline{1}] \alpha$} \\
\hline$\gamma 3$ & & {$[01 \overline{1}] \gamma / /[\overline{1} \overline{1} 1] \alpha$} \\
\hline$\gamma 4$ & & {$[01 \overline{1}] \gamma / /[\overline{1} 1 \overline{1}] \alpha$} \\
\hline$\gamma 5$ & & {$[1 \overline{1} 0] \gamma / /[\overline{1} \overline{1} 1] \alpha$} \\
\hline$\gamma 6$ & & {$[1 \overline{1} 0] \gamma / /[\overline{1} 1 \overline{1}] \alpha$} \\
\hline$\gamma 7$ & \multirow{6}{*}{$(1 \overline{1} 1) \gamma / /(011) \alpha$} & {$[10 \overline{1}] \gamma / /[\overline{1} \overline{1} 1] \alpha$} \\
\hline$\gamma 8$ & & {$[10 \overline{1}] \gamma / /[\overline{1} 1 \overline{1}] \alpha$} \\
\hline$\gamma 9$ & & {$[\overline{1} \overline{1} 0] \gamma / /[\overline{1} \overline{1} 1] \alpha$} \\
\hline$\gamma 10$ & & {$[\overline{1} \overline{1} 0] \gamma / /[\overline{1} \overline{1} 1] \alpha$} \\
\hline$\gamma 11$ & & {$[\overline{1} 01] \gamma / /[\overline{1} 1 \overline{1}] \alpha$} \\
\hline$\gamma 12$ & & {$[011] \gamma / /[\overline{1} 1 \overline{1}] \alpha$} \\
\hline$\gamma 13$ & \multirow{6}{*}{$(\overline{1} 11) \gamma / /(011) \alpha$} & {$[0 \overline{1} 1] \gamma / /[\overline{1} \overline{1} 1] \alpha$} \\
\hline$\gamma 14$ & & {$[0 \overline{1} 1] \gamma / /[\overline{1} 1 \overline{1}] \alpha$} \\
\hline$\gamma 15$ & & {$[\overline{1} 0 \overline{1}] \gamma / /[\overline{1} \overline{1} 1] \alpha$} \\
\hline$\gamma 16$ & & {$[\overline{1} 0 \overline{1}] \gamma / /[\overline{1} 1 \overline{1}] \alpha$} \\
\hline$\gamma 17$ & & {$[110] \gamma / /[\overline{1} \overline{1} 1] \alpha$} \\
\hline$\gamma 18$ & & {$[110] \gamma / /[\overline{1} 1 \overline{1}] \alpha$} \\
\hline$\gamma 19$ & \multirow{6}{*}{$(11 \overline{1}) \gamma / /(011) \alpha$} & {$[\overline{1} 10] \gamma / /[\overline{1} \overline{1} 1] \alpha$} \\
\hline$\gamma 20$ & & {$[\overline{1} 10] \gamma / /[\overline{1} 1 \overline{1}] \alpha$} \\
\hline$\gamma 21$ & & {$[0 \overline{1} \overline{1}] \gamma / /[\overline{1} \overline{1} 1] \alpha$} \\
\hline$\gamma 22$ & & {$[0 \overline{1} \overline{1}] \gamma / /[\overline{1} 1 \overline{1}] \alpha$} \\
\hline$\gamma 23$ & & {$[101] \gamma / /[\overline{1} \overline{1} 1] \alpha$} \\
\hline$\gamma 24$ & & {$[101] \gamma / /[\overline{1} 1 \overline{1}] \alpha$} \\
\hline
\end{tabular}



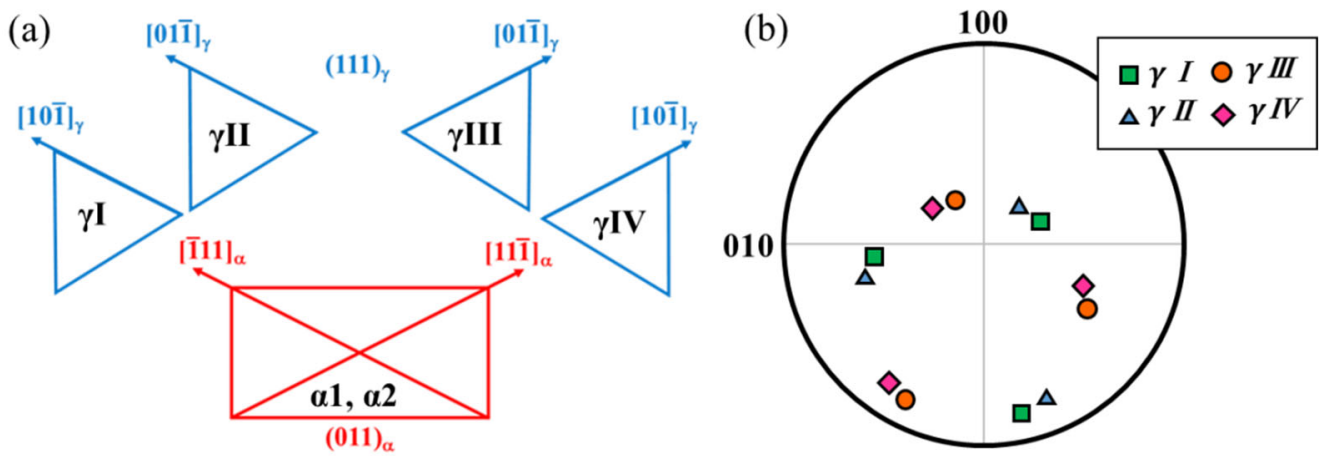

Figure 11 (a) Schematic of the four $\gamma$ variants satisfying the K-S ORs for V $\alpha 1$ and V $\alpha 2$.

(b) Stereographic projections of the corresponding four $\gamma$ variants with respect to (a).

Next, we discuss the ORs of $\theta-\alpha$. As found in Fig. 10, an Isaichev OR $((011) \alpha / /(031) \theta,[\overline{1} \overline{1} 1] \alpha / /[100] \theta)$ exists between $\theta$ and $\alpha$. Table 2 lists the 24 variants of the Isaichev OR $[45,46]$. Similar to the case of the K-S OR, the possible $\theta$ variants from $V_{\alpha 1}$ and $V_{\alpha 2}$ can be calculated using the rotating matrix $\mathbf{T}_{\text {isa. }}$ Among $\theta 1 V_{\alpha 1}-\theta 24 V_{\alpha 1}$ and $\theta 1 \mathrm{~V}_{\alpha 2}-\theta 24 \mathrm{~V}_{\alpha 2}$, the combination sharing similar (031) and [100] with a misorientation less than $10^{\circ}$ is found to be only one, as indicated by $\theta \mathrm{I}\left(\theta 4 \mathrm{~V}_{\alpha 1}-\theta 7 \mathrm{~V}_{\alpha 2}\right)$ in Fig. 12(a). Finally, the $\gamma$ variants satisfying the Pitsch OR ((031) $\theta / /$ (111) $\gamma$, $[100] \theta /[\overline{101}] \gamma)[41]$ with this $\theta \mathrm{I}$ were determined from four $\gamma$ variants of $\gamma \mathrm{I}, \gamma \mathrm{II}, \gamma \mathrm{III}$, and $\gamma \mathrm{IV}$ that satisfy the $\mathrm{K}-\mathrm{S}$ ORs with $\mathrm{V}_{\alpha 1}$ and $\mathrm{V}_{\alpha 2}$. Figure 12(b) shows the stereographic projection of this relationship and Table 3 summarizes the misorientation. Among four combinations, $\gamma \theta \mathrm{I}$ and $\gamma \mathrm{IV}$ share the same (111) and [101] with the smallest misorientation. Compared to other ORs such as $\alpha-\theta$ and $\alpha-\gamma$, the obtained misorientation of $9.8^{\circ}$ in $(111)$ and $3.0^{\circ}$ in $[\overline{101}]$ is not so small. Such large misorientation might be related to the accuracy of lattice constants of $\theta$ used in this study. Although further investigation will be needed to clarify this point, our analysis is quite suggestive of the fact that the $\mathrm{K}-\mathrm{S}$, Isaichev and Pitsch ORs may limit the possible $\gamma$ variants formed from $\alpha 1$ and $\alpha 2$ variants to only one. Figure 13 summarizes these obtained results, which suggests that the $\gamma$ memory effect originates from the variant restrictions among $\alpha-\theta-\gamma$. 
Table 2 Isaichev ORs with 24 variants.

\begin{tabular}{|c|c|c|}
\hline Variant & Plane parallel & Direction parallel \\
\hline$\theta 1$ & (031) $\theta / /(011) \alpha$ & {$[100] \theta / /[\overline{1} \overline{1} 1] \alpha$} \\
\hline$\theta 2$ & (031) $\theta / /(0 \overline{1} 1) \alpha$ & {$[100] \theta / /[11 \overline{1}] \alpha$} \\
\hline$\theta 3$ & (031) $\theta / /(01 \overline{1}) \alpha$ & {$[100] \theta / /[\overline{1} \overline{1} \overline{1}] \alpha$} \\
\hline$\theta 4$ & (031) $\theta / /(0 \overline{1} 1) \alpha$ & {$[100] \theta / /[\overline{1} 11] \alpha$} \\
\hline$\theta 5$ & (031) $\theta / /(01 \overline{1}) \alpha$ & {$[100] \theta / /[111] \alpha$} \\
\hline$\theta 6$ & (031) $\theta / /(0 \overline{1} 1) \alpha$ & {$[100] \theta / /[\overline{1} 11] \alpha$} \\
\hline$\theta 7$ & (031) $\theta / /(011) \alpha$ & {$[100] \theta / /[\overline{1} 1 \overline{1}] \alpha$} \\
\hline$\theta 8$ & $(031) \theta / /(0 \overline{1} \overline{1}) \alpha$ & {$[100] \theta / /[111] \alpha$} \\
\hline$\theta 9$ & (031) $\theta / /(\overline{1} 01) \alpha$ & {$[100] \theta / /[111] \alpha$} \\
\hline$\theta 10$ & (031) $\theta / /(10 \overline{1}) \alpha$ & {$[100] \theta / /[\overline{1} 1 \overline{1}] \alpha$} \\
\hline$\theta 11$ & (031) $\theta / /(101) \alpha$ & {$[100] \theta / /[\overline{1} \overline{1} 1] \alpha$} \\
\hline$\theta 12$ & (031) $\theta / /(\overline{1} 0 \overline{1}) \alpha$ & {$[100] \theta / /[1 \overline{1} \overline{1}] \alpha$} \\
\hline$\theta 13$ & (031) $\theta / /(101) \alpha$ & {$[100] \theta / /[11 \overline{1}] \alpha$} \\
\hline$\theta 14$ & $(031) \theta / /(\overline{1} 0 \overline{1}) \alpha$ & {$[100] \theta / /[\overline{1} 11] \alpha$} \\
\hline$\theta 15$ & (031) $\theta / /(10 \overline{1}) \alpha$ & {$[100] \theta / /[1 \overline{1} 1] \alpha$} \\
\hline$\theta 16$ & (031) $\theta / /(\overline{1} 01) \alpha$ & {$[100] \theta / /[\overline{1} \overline{1} \overline{1}] \alpha$} \\
\hline$\theta 17$ & (031) $\theta / /(\overline{1} 10) \alpha$ & {$[100] \theta / /[\overline{1} \overline{1} 1] \alpha$} \\
\hline$\theta 18$ & (031) $\theta / /(1 \overline{1} 0) \alpha$ & {$[100] \theta / /[111] \alpha$} \\
\hline$\theta 19$ & (031) $\theta / /(110) \alpha$ & {$[100] \theta / /[\overline{1} \overline{1} 1] \alpha$} \\
\hline$\theta 20$ & $(031) \theta / /(\overline{1} \overline{1} 0) \alpha$ & {$[100] \theta / /[\overline{1} 1 \overline{1}] \alpha$} \\
\hline$\theta 21$ & (031) $\theta / /(110) \alpha$ & {$[100] \theta / /[\overline{1} 1 \overline{1}] \alpha$} \\
\hline$\theta 22$ & $(031) \theta / /(\overline{1} \overline{1} 0) \alpha$ & {$[100] \theta / /[1 \overline{1} 1] \alpha$} \\
\hline$\theta 23$ & $(031) \theta / /(1 \overline{1} 0) \alpha$ & {$[100] \theta / /[\overline{1} \overline{1} \overline{1}] \alpha$} \\
\hline$\theta 24$ & (031) $\theta / /(\overline{1} 10) \alpha$ & {$[100] \theta / /[11 \overline{1}] \alpha$} \\
\hline
\end{tabular}


(a)

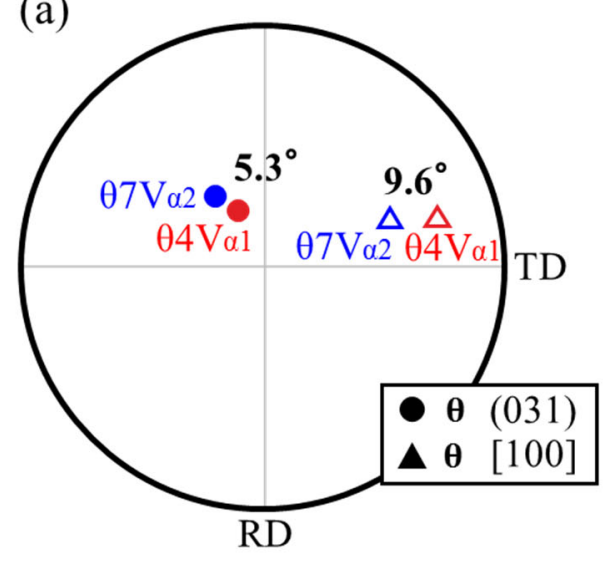

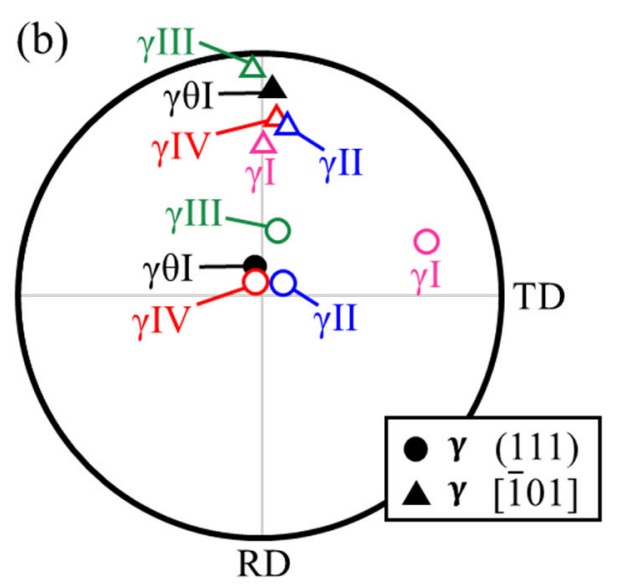

Figure 12 Analytically obtained stereographic projections of (a) $\theta$ - $\alpha$, and (b) $\gamma \mathrm{I}, \gamma \mathrm{II}, \gamma \mathrm{III}$, $\gamma \mathrm{IV}$ (K-S OR) $-\gamma \theta \mathrm{I}$ (Pitsch OR). The numbers seen in the figure indicate the misorientation degrees.

Table 3 Summary of misorientations between $\gamma \mathrm{I}, \gamma \mathrm{II}, \gamma \mathrm{III}, \gamma \mathrm{IV}$ (K-S OR) and $\gamma \theta \mathrm{I}$ (Pitsch OR).

\begin{tabular}{|l|l|l|}
\hline & $(\mathbf{1 1 1})$ & {$[\overline{\mathbf{1 0 1}}]$} \\
\hline$\gamma \mathrm{I}$ & $81.2^{\circ}$ & $1.4^{\circ}$ \\
\hline$\gamma \mathrm{II}$ & $66.5^{\circ}$ & $6.1^{\circ}$ \\
\hline$\gamma \mathrm{III}$ & $23.8^{\circ}$ & $5.2^{\circ}$ \\
\hline$\gamma \mathrm{IV}$ & $9.8^{\circ}$ & $3.0^{\circ}$ \\
\hline
\end{tabular}




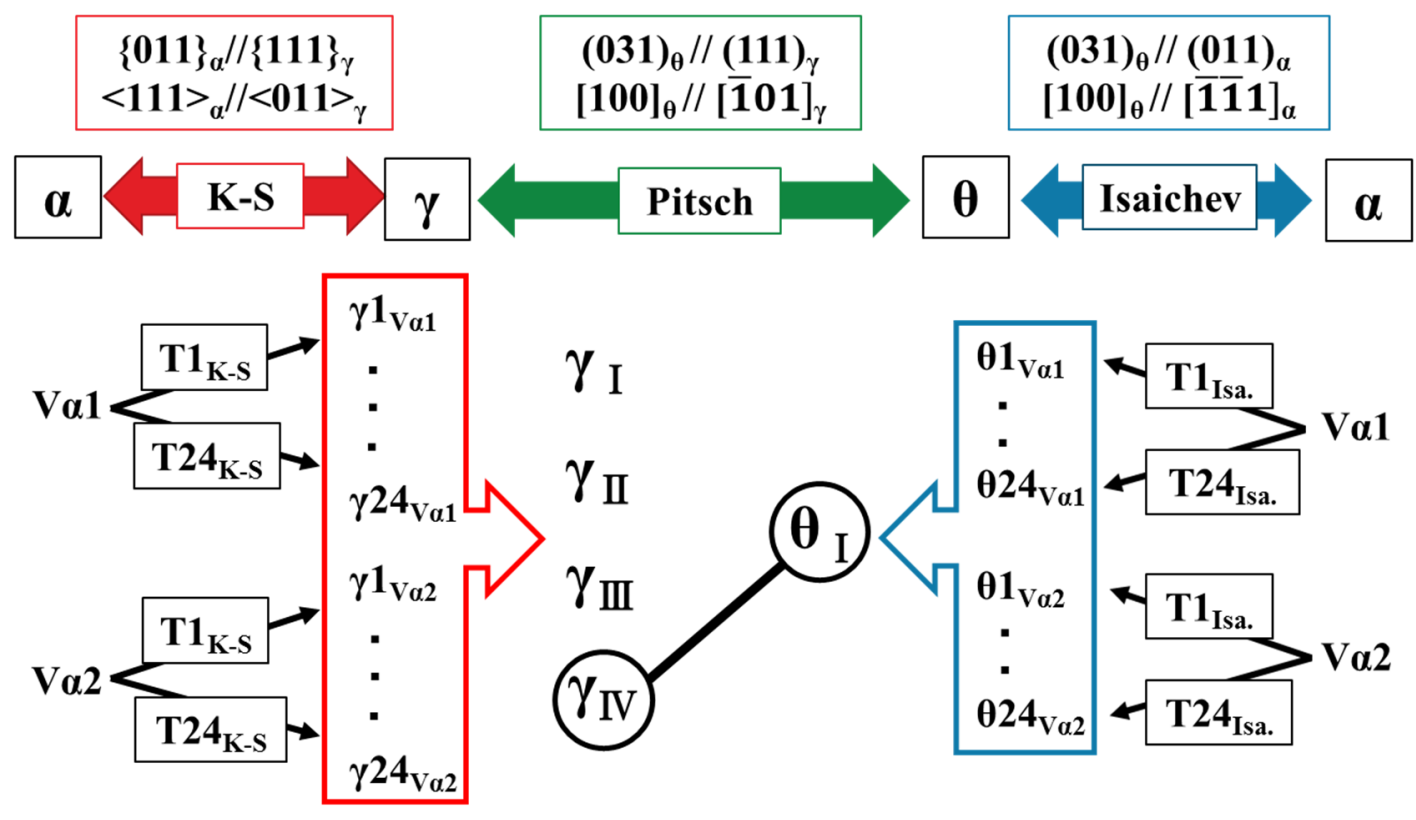

Figure 13 Variant restrictions among $\alpha-\theta-\gamma$, explaining the origin of $\gamma$ memory effect. 
Now let us summarize the results. When the sample solution-treated at $1300{ }^{\circ} \mathrm{C}$ without any subsequent heat treatment was inversely transformed at a high heating rate, the $\gamma$ memory effect was suppressed, while the slow heating induced the $\gamma$ memory effect. During slow heating, the coarse and stable $\theta$ precipitated on lath boundary, and reversely transformed $\gamma$ is considered to form adjacent to $\theta$. To confirm the effect of coarse $\theta$ on the $\gamma$ memory effect, the sample was tempered at $700{ }^{\circ} \mathrm{C}$ for 24 hours, and TEM observation revealed the existence of coarse $\theta$ in the tempered sample. The in-situ SEM-EBSD observation clarified that the rapid heating of the tempered sample also induced the $\gamma$ memory effect. Furthermore, crystal orientation analysis confirmed the existence of $\mathrm{K}-\mathrm{S}$ OR between $\gamma-\alpha 1$ and $\gamma-\alpha 2$, Isaichev OR between $\alpha 1-\theta$ and $\alpha 2-\theta$, and Pitsch OR between $\theta$ and $\gamma$. For all possible combinations, the reversely transformed $\gamma$ satisfying K-S OR for $\alpha 1$ and $\alpha 2$ is limited to four variants. The $\theta$ variant satisfying the Isaichev OR with $V_{\alpha 1}$ and $\mathrm{V}_{\alpha_{2}}$ is limited to one variant, which matches with one of the four variants by the Pitsch OR. Our analysis indicates that the $\gamma$ memory effect should be associated with the variant restrictions among $\alpha-\theta-\gamma$. However, note that our focus was directed at the formation of $\gamma$ from two $\alpha$ variants. To investigate the $\gamma$ memory effect more deeply, the analysis of reversely transformed $\gamma$ generated at various sites will be required. 


\section{Conclusions}

This study investigated the effect of heating rate on the reversely transformed $\gamma$ from martensite using in-situ electron backscatter diffraction. The origin of the $\gamma$ memory effect was discussed based on the ORs of $\alpha-\theta-\gamma$. The following conclusions can be drawn from this study:

(1) When the sample solution-treated at $1300{ }^{\circ} \mathrm{C}$ and then water-quenched was heated to $780{ }^{\circ} \mathrm{C}$, the heating rate affected the $\gamma$ memory effect. A slow heating induced the $\gamma$ memory effect, under which coarse $\gamma$ grains were formed. A rapid heating enhanced the formation of fine globular $\gamma$ grains.

(2) When globular $\gamma$ and acicular $\gamma$ grains co-existed, the latter grains encroached by the former grains because of the high strain in the latter grains.

(3) At both high and low heating rates, the formation of $\theta$ in martensite led to the $\gamma$ memory effect.

(4) In-situ SEM-EBSD analysis showed that $\gamma$ grain formed adjacent to $\theta$ at the boundary between two $\alpha$ variants. Importantly, $\theta$ exhibits Isaichev OR with both $\alpha$ variants, $\gamma$ exhibits KS OR with both $\alpha$ variants and $\gamma$ satisfies Pitsch OR with $\theta$.

(5) The variant analysis indicates that $\theta$ variant satisfying the Isaichev OR with two $\alpha$ variants is limited to one variant and $\gamma$ variant satisfying $\mathrm{K}-\mathrm{S}$ OR with two $\alpha$ variants is limited to four variants. The four variants are further limited to only one variant when Pitsch OR exists between $\gamma$ and $\theta$. It is suggested that the $\gamma$ memory effect is closely associated with the variant restrictions among $\alpha-\theta-\gamma$.

\section{Declarations of interest}

None. 


\section{References:}

[1] H.G. Tehrani-Moghadam, H.R. Jafarian, M.T. Salehi, A.R. Eivani, Evolution of microstructure and mechanical properties of Fe-24Ni-0.3C TRIP steel during friction stir processing, Materials Science and Engineering: A 718 (2018) 335-344.

[2] M. Eskandari, A. Zarei-Hanzaki, M.A. Mohtadi-Bonab, Y. Onuki, R. Basu, A. Asghari, J.A. Szpunar, Grain-orientation-dependent of $\gamma-\varepsilon-\alpha^{\prime}$ transformation and twinning in a super-high-strength, high ductility austenitic Mn-steel, Materials Science and Engineering: A 674 (2016) 514-528.

[3] T. Kaneshita, G. Miyamoto, T. Furuhara, Variant selection in grain boundary nucleation of bainite in Fe-2Mn-C alloys, Acta Materialia 127 (2017) $368-378$.

[4] A.S. Hamada, A.P. Kisko, P. Sahu, L.P. Karjalainen, Enhancement of mechanical properties of a TRIP-aided austenitic stainless steel by controlled reversion annealing, Materials Science and Engineering: A 628 (2015) 154-159.

[5] A. Alaei, H. Jafarian, A.R. Eivani, Observation austenite memory and significant enhancement of tensile properties during cyclic reverse martensite transformation in a Fe-Ni-C TRIP steel, Materials Science and Engineering: A 676 (2016) 342-350.

[6] X. Sun, Z. Li, Q. Yong, Z. Yang, H. Dong, Y. Weng, Third generation high strength low alloy steels with improved toughness, Science China Technological Sciences 55(7) (2012) 1797-1805.

[7] E.O. Hall, The Deformation and Ageing of Mild Steel: III Discussion of Results, Proceedings of the Physical Society. Section B 64(9) (1951) 747.

[8] M. Eskandari, A. Najafizadeh, A. Kermanpur, Effect of strain-induced martensite on the formation of nanocrystalline 316L stainless steel after cold rolling and annealing, Materials Science and Engineering: A 519(1) (2009) 46-50.

[9] H. Jafarian, A.J.J.o.M.S. Eivani, Texture development and microstructure evolution in metastable austenitic steel processed by accumulative roll bonding and subsequent annealing, Journal of Materials Science 49(19) (2014) 6570-6578.

[10] H.R. Jafarian, S.H.M. Anijdan, A.R. Eivani, N. Park, A comprehensive study of microstructure development and its corresponding tensile properties in nano/ultrafine-grained metastable austenitic steel during accumulative roll bonding (ARB), Materials Science and Engineering: A 703 (2017) 196-204. [11] H. Nozaki, Y. Nishikawa, Y. Uesugi, I. Tamura, Change in the Austenite Grain Size Due to Temperature Cycling, Tetsu-to-Hagane 72(10) (1986) 1598-1604.

[12] A. Kościelna, W. Szkliniarz, Effect of cyclic heat treatment parameters on the grain refinement of $\mathrm{Ti}-48 \mathrm{Al}-2 \mathrm{Cr}-2 \mathrm{Nb}$ alloy, Materials Characterization 60(10) (2009) 1158-1162.

[13] R. Radis, S. Schwarz, S. Zamberger, E. Kozeschnik, AlN Precipitation During Isothermal Annealing of Ultra Low Carbon Steel, steel research international 82(8) (2011) 905-910.

[14] S. Matsuda, Y. Okamura, Reverse Transformation of Low-carbon Low Alloy Steels, Tetsu-to-Hagane 60(2) (1974) $226-238$.

[15] Y.A. Bagaryatskii, The probable mechanism of the martensite decomposition, H. Brutcher Technical Translations 1950. 
[16] S.T. Kimmins, D.J. Gooch, Austenite memory effect in 1 Cr-1 Mo-0·75V(Ti, B) steel, Metal Science 17(11) (1983) 519-532.

[17] T. Hara, N. Maruyama, Y. Shinohara, H. Asahi, G. Shigesato, M. Sugiyama, T. Koseki, Abnormal \&alpha; to \&gamma; Transformation Behavior of Steels with a Martensite and Bainite Microstructure at a Slow Reheating Rate, ISIJ International 49(11) (2009) 1792-1800.

[18] T. Shinozaki, Y. Tomota, T. Fukino, T. Suzuki, Microstructure Evolution during Reverse Transformation of Austenite from Tempered Martensite in Low Alloy Steel, ISIJ International advpub (2017).

[19] Y. Tomota, W. Gong, S. Harjo, T. Shinozaki, Reverse austenite transformation behavior in a tempered martensite low-alloy steel studied using in situ neutron diffraction, Scripta Materialia 133 (2017) 79-82.

[20] X. Zhang, G. Miyamoto, Y. Toji, T. Furuhara, Effects of Heating Rate on Formation of Globular and Acicular Austenite during Reversion from Martensite, Metals 9(2) (2019) 266.

[21] R.A. Grange, The rapid heat treatment of steel, Metallurgical Transactions 2(1) (1971) 65-78.

[22] J. Han, Y.-K. Lee, The effects of the heating rate on the reverse transformation mechanism and the phase stability of reverted austenite in medium Mn steels, Acta Materialia 67 (2014) 354-361.

[23] N. Nakada, R. Fukagawa, T. Tsuchiyama, S. Takaki, D. Ponge, D. Raabe, Inheritance of Dislocations and Crystallographic Texture during Martensitic Reversion into Austenite, ISIJ International 53(7) (2013) 1286-1288

[24] S. Watanabe, T. Kinitake, On the Formation of Austenite Grains from Prior Martensitic Structure, Tetsu-to-Hagane 61(1) (1975) 96-106.

[25] N. Nakada, T. Tsuchiyama, S. Takaki, S. Hashizume, Variant Selection of Reversed Austenite in Lath Martensite, ISIJ International 47(10) (2007) $1527-1532$.

[26] T. Tomida, Variant selection mechanism by elastic anisotropy and double K-S relation for transformation texture in steel; difference between martensite and ferrite, Acta Materialia 146 (2018) 25-41.

[27] I. Lischewski, G. Gottstein, Nucleation and variant selection during the $\alpha-\gamma-\alpha$ phase transformation in microalloyed steel, Acta Materialia 59(4) (2011) 1530-1541.

[28] A.J. Schwartz, M. Kumar, B.L. Adams, D.P. Field, Electron backscatter diffraction in materials science, Springer2000.

[29] Y. Tomota, N. Sekido, S. Harjo, T. Kawasaki, W. Gong, A. Taniyama, $<\mathrm{i}>\mathrm{In}$ situ $</ \mathrm{i}>$ Observations of Transformation Behavior upon Heating for a 1.5Mn-1.5Si-0.2C Steel -Comparison between Neutron Diffraction, XRD, EBSD and Dilatometry, ISIJ International 57(12) (2017) $2237-2244$.

[30] N. Nakada, Direct observation of martensitic reversion from lenticular martensite to austenite in Fe-Ni alloy, Materials Letters 187 (2017) 166-169.

[31] T. Morimoto, F. Yoshida, I. Chikushi, H. Kitahara, N. Tsuji, Development of Variant Analysis Program by Using EBSD Data, Tetsu-to-Hagane 93(9) (2007) 591-599.

[32] G. Miyamoto, N. Takayama, T. Furuhara, Accurate measurement of the orientation relationship of lath martensite and bainite by electron backscatter 
diffraction analysis, Scripta Materialia 60(12) (2009) 1113-1116.

[33] G. Miyamoto, N. Iwata, N. Takayama, T. Furuhara, Mapping the parent austenite orientation reconstructed from the orientation of martensite by EBSD and its application to ausformed martensite, Acta Materialia 58(19) (2010) 6393-6403.

[34] G. Miyamoto, N. Iwata, N. Takayama, T. Furuhara, Reconstruction of Parent Austenite Grain Structure Based on Crystal Orientation Map of Bainite with and without Ausforming, ISIJ International 51(7) (2011) 1174-1178

[35] X. Zhang, G. Miyamoto, Y. Toji, S. Nambu, T. Koseki, T. Furuhara, Orientation of austenite reverted from martensite in Fe-2Mn-1.5Si-0.3C alloy, Acta Materialia 144 (2018) 601-612.

[36] Thermo-Calc Software TCFE9 Database (Accessed 1 Jul 2019).

[37] T. Furuhara, K. Kobayashi, T. Maki, Control of Cementite Precipitation in Lath Martensite by Rapid Heating and Tempering, ISIJ International 44(11) (2004) 1937-1944.

[38] H. Luo, J. Shi, C. Wang, W. Cao, X. Sun, H. Dong, Experimental and numerical analysis on formation of stable austenite during the intercritical annealing of 5Mn steel, Acta Materialia 59(10) (2011) 4002-4014.

[39] C.C. Kinney, K.R. Pytlewski, A.G. Khachaturyan, J.W. Morris, The microstructure of lath martensite in quenched 9Ni steel, Acta Materialia 69 (2014) $372-385$

[40] I. Isaichev, Orientation of cementite in tempered carbon steel, J Zh Sakharnoi Promst 17 (1947) 835-838.

[41] S.W. Thompson, P.R. Howell, A preliminary comparison of two apparently diverse cementite/austenite orientation relationships, Scripta Metallurgica $22(2)(1988) 229-233$

[42] S. Morito, H. Tanaka, R. Konishi, T. Furuhara, T. Maki, The morphology and crystallography of lath martensite in Fe-C alloys, Acta Materialia 51(6) (2003) 1789-1799

[43] H. Kitahara, R. Ueji, N. Tsuji, Y. Minamino, Crystallographic features of lath martensite in low-carbon steel, Acta Materialia 54(5) (2006) 12791288

[44] H. Kitahara, R. Ueji, M. Ueda, N. Tsuji, Y. Minamino, Crystallographic analysis of plate martensite in Fe-28.5 at.\% Ni by FE-SEM/EBSD, Materials Characterization 54(4) (2005) 378-386.

[45] S.V. Prikhodko, A.S. Prudnikov, R.V. Televich, TEM Study of the Selectivity of Crystallographic Variants of the Orientation Relationships of Cementite in an Aged Low-Carbon Martensitic Steel, Microscopy and Microanalysis 11(S02) (2005) 2016-2017.

[46] E.V. Pereloma, I.B. Timokhina, S.P. Swenser, Formation of cementite in tempered Fe-Co-C alloys, Micron 32(8) (2001) 825-829. 